\title{
Adverse Effects of Energy Drinks, a Challenge for Medicine: A Case Report
}

\author{
Paola Silva-Maldonado', Esther Ramírez-Moreno르, Luis Arturo Rivera-Ramírez², Angélica \\ Romero-Palencia ${ }^{3}$, María Luisa Sánchez-Padilla ${ }^{4}$, Reyna Cristina Jiménez-Sánchez ${ }^{4}$ and José \\ Arias-Rico ${ }^{4 *}$
}

${ }^{1}$ Docotorate in Food and Human Health, Autonomous University of the State of Hidalgo, Mexico

${ }^{2}$ Master in Public Health, Autonomous University of the State of Hidalgo, Mexico

${ }^{3}$ Academic Area of Psychology, Autonomous University of the State of Hidalgo, Mexico

${ }^{4}$ Academic Nursing Area, Autonomous University of the State of Hidalgo, Mexico

*Corresponding author: José Arias-Rico, Academic Nursing Area, Institute of Health Sciences, Autonomous University of the State of Hidalgo, Ex Hacienda La Concepción S/N Circuit, Pachuca-Actopan Highway, C.P. 42160 San Agustín Tlaxiaca, Hidalgo, Mexico.

To Cite This Article: Paola Silva-Maldonado, Esther Ramírez-Moreno, Luis Arturo Rivera-Ramírez, Angelica Romero-Palencia, María Luisa Sánchez-Padilla, Reyna Cristina Jiménez-Sánchez, José Arias-Rico, Adverse Effects of Energy Drinks, a Challenge for Medicine: A Case Report. Am J Biomed Sci \& Res. 2020 - 11(3). AJBSR.MS.ID.001635. DOI: 10.34297/AJBSR.2020.11.001635.

Received: 眥 August 16, 2020; Published: 䟧 December 21, 2020

\begin{abstract}
In Mexico, an estimate of the monthly average consumption of these drinks was 36,240,000 liters [1]. The use of these products is to increase energy levels during physical activity or exam periods to avoid sleep. Despite the increase in its use, there is ignorance in its consumers about its level of safety in its consumption [2]. Energy drinks (ED) appeared on the market as a mixture of carbohydrates, vitamins, and caffeine. Later, alcohol blends were made for cocktails, so their popularity increased. The high consumption of ED is due to the mental stimulating effect by the high levels of caffeine, taurine and glucuronolactone [3].

The case of a patient is reported who presents jaundice and an abnormal liver function with symptoms of a disease sui generis, after two weeks of consuming ED. He was not diagnosed since the symptoms still represent a challenge for medicine. When the patient stop pending the use consumption of ED, the patient took 30 days passed before for his liver function tests and his clinical picture were normalized.
\end{abstract}

Keywords: Energy drinks; Teenagers; Cardiac arrhythmias; Adverse effects; Caffeine; Taurine

\section{Implication and Contribution}

One patient presents with jaundice and abnormal liver function tests with symptoms of a disease sui generis, after 2 two weeks of consuming energy drinks. He was not diagnosed since the symptoms still represent a challenge for medicine. However, when stopping the consumption of these drinks, the patient took 30 days passed before his for-liver function tests and his clinical picture to were normalize.

\section{Case Report}

A 19-year-old, single undergraduate male patient, with domicile in the state of Hidalgo, Mexico, came to the clinic for the first time with a seven-day clinical picture including: with seven days of evolution: tiredness, dizziness, vertigo, chest tightness, headache, low back pain, heartburn, dysuria, tinnitus, paresthesia's in upper and lower limbs, and generalized excessive diaphoresis.

In the family history, the patient reported myopia, astigmatism, and a molar extraction one a year ago, denied neurological and allergic problems. He presented suicidal ideas his paternal grandfather had diabetes, and his maternal grandfather had a pacemaker. He denied the use of tobacco but does drank alcohol occasionally drink alcohol. In addition, he says that during the last two weeks he has took consumed $500 \mathrm{~mL} /$ day of ED with the aim 
of increasing his physical activity, reducing fatigue and tiredness. Different exams were carried out with the presumed diagnosis of icteric syndrome in study: hematic biometry, blood chemistry, liver function tests, urine general study and abdominal ultrasound. In hematic biometry, an increase in erythrocytes was observed (6.26 x106/mm3); hemoglobin (18.3 g/dL) and hematocrit (55.6\%) were above normal level. Blood chemistry analysis showed an increase in total bilirubin $(1.51 \mathrm{mg} / \mathrm{dL})$, direct bilirubin $(0.27 \mathrm{mg} / \mathrm{dL})$; and
Indirect bilirubin $(1.24 \mathrm{mg} / \mathrm{dL})$ (Table 1$)$. The urine general test was normal, and the result of diagnostic tests for hepatitis was negative. In liver function tests, they were performed on days 0 and 30 , without significant alteration (Table 2). Hepatic gland without focal or diffuse lesions, gallbladder, spleen, and kidneys without data that suggested any pathology was reported in the abdominal USG (Figure 1).

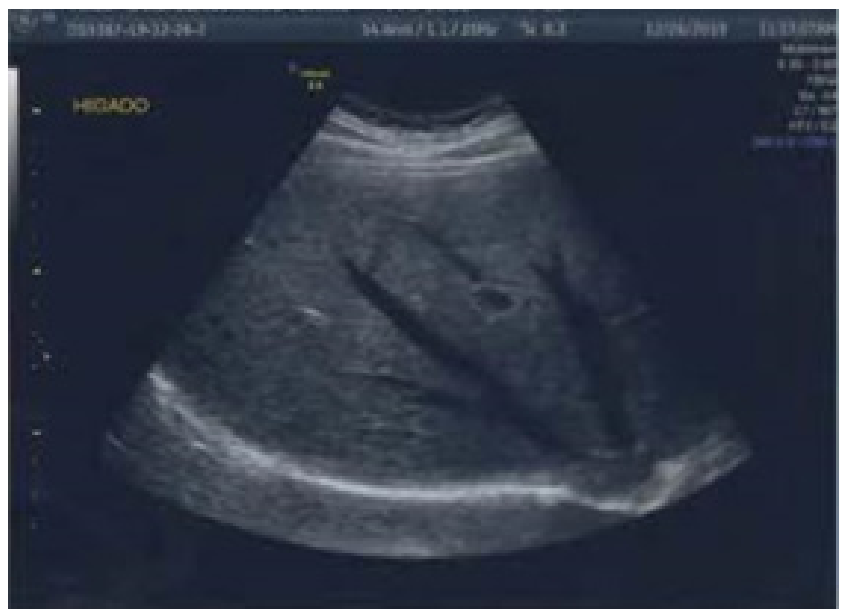

Figure 1: USG images of liver and bile ducts performed on day zero.

Table 1: Results of Hematic Biometry and Blood Chemistry.

\begin{tabular}{|c|c|c|c|c|}
\hline \multicolumn{5}{|c|}{ Hematic biometry } \\
\hline & Day 0 & Day 15 & Day 30 & Reference values \\
\hline Erythrocytes $\left(\mathrm{x} 10^{6} / \mathrm{mm}^{3}\right)$ & 6.26 & 6.04 & 6.01 & $4.7-6.1$ \\
\hline Hemoglobin (g/dL) & 18.3 & 17.7 & 17.7 & $13.2-17.2$ \\
\hline Hematocrit (\%) & 55.6 & 53.6 & 53.6 & $42-52$ \\
\hline Total leucocytes $(/ \mathrm{uL})$ & 5800 & 4200 & 6600 & $450-11000$ \\
\hline \multicolumn{5}{|c|}{ Blood chemistry } \\
\hline Serum glucose (mg/dL) & 79 & 78 & 85 & $70-100$ \\
\hline Total serum cholesterol (mg/dL) & 138 & 141 & 142 & $<200$ \\
\hline Serum triglycerides (mg/dL) & 176 & 136 & 118 & $<150$ \\
\hline Total bilirubin in serum (mg/dL) & 1.51 & 1.68 & 1.18 & $0.3-1.0$ \\
\hline Direct bilirubin serum (mg/dL) & 0.27 & 0.29 & 0.21 & $0.0-0.18$ \\
\hline Indirect bilirubin serum (mg/dL) & 1.24 & 1.39 & 0.97 & $0.0-1.0$ \\
\hline
\end{tabular}

Source: Laboratories, performed on days 0,15 and 30 .

Table 2: Results of liver function tests.

\begin{tabular}{|c|c|c|c|}
\hline & Day 0 & Day 15 & Reference values \\
\hline Lactic dehydrogenase (DHL) in serum (U/L) & 146 & 14 & $100-271$ \\
\hline Alkaline phosphatase (ALP) in serum (U/L) & 108 & 100 & $30-120$ \\
\hline Gamma-glutamyl transpeptidase (GGT) in serum (U/L) & 38 & 29 & $9-64$ \\
\hline Serum amylase (U/L) & 62 & 64 & $29-103$ \\
\hline Serum lipase (U/L) & 19 & 16 & $11-82$ \\
\hline Total serum proteins $(\mathrm{g} / \mathrm{dL})$ & 7.1 & 7.39 & $6.4-8.9$ \\
\hline
\end{tabular}




\begin{tabular}{|c|c|c|c|}
\hline Serum albumin $(g / d L)$ & 4.79 & 4.97 & $3.5-5.7$ \\
\hline Globulins in serum $(\mathrm{g} / \mathrm{dL})$ & 2.31 & 2.42 & $2.0-3.5$ \\
\hline Albumin / globulin ratio & 2.07 & 2.05 & $>1.0$ \\
\hline Serum sodium (mmol/L) & 138.1 & 137.7 & $136-146$ \\
\hline Serum potassium $(\mathrm{mmol} / \mathrm{L})$ & 4.3 & 4.5 & 3.5-5.1 \\
\hline Serum chlorine (mmol/L) & 103.9 & 104.2 & 101-109 \\
\hline Serum calcium(mg/dL) & 9.8 & 9.6 & 8.6-10.3 \\
\hline Serum phosphorus (mg/dL) & 4 & 3.3 & $2.5-5.0$ \\
\hline Serum magnesium (mg/dL) & 1.9 & & $1.9-2.7$ \\
\hline Serum osmolarity (mOsm/Kg) & 285 & & $275-295$ \\
\hline Serum iron (ug/dL) & 78 & & $50-212$ \\
\hline Unsaturated Iron Fixing Capacity (ug/dL) & 359 & & $155-355$ \\
\hline Total Iron Fixing Capacity (ug/dL) & 437 & & $250-350$ \\
\hline
\end{tabular}

Source: Laboratories, performed on days 0,15 and 30 .

The patient was instructed to stop drink the DE to start rehydration, accompanied by antihypertensive and antiarrhythmic treatment for one week, with an open appointment to the emergency department and appointment at 15 and 30 days. In addition, due to the history of suicidal thoughts, he was referred to a consultation with psychology.

A trend towards improvement of erythrocytes, hemoglobin and hematocrit was reported in Hematic Biometry of subsequent consultation. Blood chemistry analysis showed an increase in total, direct and indirect bilirubin (Table 1). After of the analysis of the signs and symptoms presented by the patient and the results of cabinet studies, the diagnosis of Icteric Syndrome secondary to probable exposure of ED was managed.

For the psychological evaluation of the effects of ED on mental health, the acceptance of informed consent and the International Neuropsychiatric Interview (INI) was requested [4]. The main Axis I psychiatric disorders of DSM-IV and ICD-10 (which is a structured instrument of short duration and exploration) and Beck's Anxiety and Depression Inventories were applied [5] in order to confirm data obtained by INI. The patient had an inadequate level of introspection, anxious and depressive symptoms without previous history, a manic episode with a tendency to risk behaviors such as driving at high speed, restlessness, inattention and high level of alertness.

Thirty days after the medical consultation, a major depressive episode, melancholic symptoms, mild suicide risk, maintenance of a manic episode, panic disorder and current post-traumatic stress, and generalized anxiety were detected. In both evaluations, psychotic symptoms were ruled out. He was referred to the mental health service for psychiatric evaluation, without knowing the current results of his treatment.

\section{Discussion}

EDs are consumed mainly by adolescents and young adults. However, many of them do not known the characteristics, ingredients, safety level in their consumption, health effects, especially if DE are consumed in excess or mixed with other drugs as alcohol [2,6]. A bottle of these drinks is equivalent to three cups of coffee and contains between five and seven tablespoons of sugar [7]. Excessive consumption of DE can lead to an overdose of caffeine with detrimental effects in the health as headache, tachycardia, dry mouth, nausea, vomiting, diarrhea, stress, physical exhaustion, impaired coordination, disorientation, insomnia, hallucinations, anxiety, and depression, delirium, excitement tremors, and seizures [8]. As a result of multiple activities and limited time to rest. Most of these physiological and neurological changes were reported by the case study. At a cardiovascular and hepatic level, increased blood pressure, tachyarrhythmias and dyslipidemias have been reported in people who consume them regularly. Additionally, heart attacks, irreversible neurological injury, liver effects, and caffeine dependence have been documented. Liver dysfunction may be due to the fact that taurine is conjugated to secondary bile acids $[9,10]$ reported anxiety, restlessness, irritability, difficulty concentrating, as well as trouble sleeping after the ingestion of 200 to 250 milliliters of ED daily during those 4 months in a psychiatric case report [10]. Even with the consumption of a higher amount (14 bottles of ED containing $250 \mathrm{~mL}$ ) for two days, the risk of a suicide attempts a exists suicide [11]. There are no studies demonstrating the beneficial effects of ED, but there is sufficient evidence of the adverse effects of some of its more common components. Information should be provided to the general population on the indiscriminate use of this type of beverages, and further studies on the effects of short, medium and long-term consumption are necessary to determine with certainty the safety of ED. Therefore, 
the risk of cardiovascular, neurological, and liver damages, if it is, if ED are consumed without responsibility, are emphasized.

\section{Acknowledgments}

None of the authors received a grant or funding for this paper.

\section{References}

1. El Financiero (2018) Monster, Red Bull y Vive 100 se 'energizan' en México.

2. Arias J, Jaramillo O, Ramirez V, Bautista M, Ramirez E et al. (2019) Hypertensive and arrhythmogenic effects of an energizing naturist supplement in young university students in the state of Hidalgo. Neuroscience Meeting Planner. Chicago IL: 618-797.

3. Boris AA (2013) PorfírioPorfirio Ecos Huanaco LCSA. Intoxicación aguda por energizantes: taurina presentación de un caso clínico. Rev Inst Médico Sucre 142: 29-32.

4. Sheehan D, Janavs J, Baker R, Harnett-SK, Knapp E, et al. (2000) MIN International Neuropsychiatric Interview (M.I.N.I.): the development and validation of a structured diagnostic psychiatric interview for DSMIV and ICD-10. J Clin Psychiatry 20: 22-23.
5. Beck R, Perkins TS (2001) Cognitive Content-Specificity for Anxiety and Depression: A Meta-Analysis. Cognit Ther Res [Internet] 25(6): 651-663.

6. Sánchez J, Romero C, Arroyave C, García M, Giraldo F, et al. (2015) Bebidas energizantes: efectos benéficos y perjudiciales para la salud. Perspect Nutr Humana 17 (1): 79-91.

7. Toribio-G, Yesenia, López V, Obdulia, Navarro C, et al. (2017) Conocimiento sobre las bebidas energizantes y frecuencia de consumo en una población de estudiantes universitarios. Rev Ciencias la Salud [Internet] 4(13): 14-21.

8. Beltrán K, Cardona W (2017) Efectos médicos del consumo de bebidas energéticas. Revisión de la literatura. Medical and dental effects of energy drinks consumption. Literature review. Int J Med Surg Sci 4(2): 1167-1173.

9. Cañas DP (2002) Rol biológico y nutricional de la taurina y sus derivados. Rev. Cchil. Nnutr 29(3): 286-292.

10. Berigan T (2005) An anxiety disorder secondary to energy drinks: a case report. Psychiatry (Edgmont) 2(10): 10.

11. Szpak A, Allen D (2017) A case of acute suicidality following excessive caffeine intake. Journal of Psychopharmacology 26(11): 1502-1504. 